\title{
ANÁLISIS MOLECULAR DE LA DIVERSIDAD GENÉTICA DE FRIJOL COMÚN MANEJADA POR CAMPESINOS EN CUBA ${ }^{1}$
}

\author{
Sandra Miranda-Lorigados ${ }^{2}$, Juan Carlos Rosas-Sotomayor ${ }^{3}$, Luwbia Liudmila Aranda-Rocha ${ }^{3}$, \\ Rodobaldo Ortiz-Pérez ${ }^{2}$, Manuel Ponce-Brito ${ }^{2}$, Humberto Ríos-Labrada ${ }^{2}$
}

\begin{abstract}
RESUMEN
Análisis molecular de la diversidad genética de frijol común manejada por campesinos en Cuba. La variación genética de 27 accesiones locales de frijol común colectadas en la comunidad de El Tejar - La Jocuma, provincia Pinar del Río, Cuba, se evaluó utilizando marcadores moleculares RAPD (Polimorfismos de ADN Amplificados al Azar) y caracteres morfológicos y agronómicos. En total se emplearon 15 cebadores RAPD que generaron 31 fragmentos polimórficos de ADN (un promedio de 2,03 fragmentos por cebador). Las distancias genéticas fueron calculadas utilizando el coeficiente de similitud de Sorensen-Dice, y representadas mediante un dendograma (método UPGMA). Se evaluaron una serie de caracteres morfológicos y agronómicos con los que se realizaron análisis multivariados que generaron un clúster (distancias euclidianas) y un análisis de componentes principales. El análisis generado a partir de los marcadores RAPD y de los caracteres morfo agronómicos, reveló que las accesiones estudiadas generaron dos grupos principales que corresponden presumiblemente a los acervos Mesoamericano y Andino, considerando las distancias genéticas entre grupos y las diferencias en determinados caracteres morfológicos y agronómicos.
\end{abstract}

Palabras clave: Marcadores RAPD, caracteres morfológicos y agronómicos, diversidad, variedades locales.

\begin{abstract}
Molecular analysis of genetic diversity in Cuban landraces of common bean managed by farmers in Cuba. The genetic variation of 27 common bean landraces (Phaseolus vulgaris L.) collected in La Palma, Pinar del Río, Cuba, was evaluated using RAPD (Random Amplified Polymorphic DNA) markers and morphologic and agronomic traits. A total of 31 DNA fragments were obtained using 15 RAPD primers (averaging 2.03 per primer). Genetic distances were calculated using Sorensen-Dice's similarity coefficient and displayed in a dendrogram (UPGMA method). A multivariate analysis was also done using evaluations of morphologic and agronomic traits resulting in a dendrogram (Euclidianes distances) and main component analysis. Both RAPD and morphologic and agronomic traits clustered the accessions into two main groups that probably belong to the Mesoamerican and Andean domestication centers considering genetics distances between the groups and differences in some specific morphologic and agronomic traits.
\end{abstract}

Key words: RAPD markers, morphologic and agronomic traits, multivariate analysis, diversity, landraces.

\section{INTRODUCCIÓN}

El frijol común (Phaseolus vulgaris L.) forma parte de la dieta básica de la población cubana y constituye la fuente de la quinta parte de las proteínas totales consumidas en Cuba. Se estima que en este país se produjeron 119.800 toneladas de frijol en el año 2002, lo que constituyó más de la mitad de la demanda nacional. Durante la última década, la producción de frijol en Cuba, estuvo a cargo del sector agrícola no estatal,

\footnotetext{
1 Recibido: 2 de mayo, 2005. Aceptado: 24 de agosto, 2006. Este trabajo forma parte del contenido de la tesis de maestría presentada por la primera autora en el 2005 bajo el título "Efectividad de la selección participativa de variedades como una alternativa para el fortalecimiento de los sistemas locales de semillas de frijol común (Phaseolus vulgaris L.) en una comunidad rural cubana". Tesis de maestría, Instituto Nacional de Ciencias Agrícolas, La Habana, Cuba.

2 Instituto Nacional de Ciencias Agrícolas, Gaveta Postal \# 1, San José de las Lajas, La Habana, Cuba. Correo electrónico: sandra@inca.edu.cu

3 Escuela Agrícola Panamericana/Zamorano, Apartado Postal 93, Tegucigalpa, Honduras. Correo electrónico: jcrosas@ zamorano.edu
} 
constituido fundamentalmente por fincas y pequeñas parcelas, con condiciones muy diversas y baja disponibilidad de insumos agroquímicos y energéticos (García et al. 1997). En estas condiciones, la producción de frijol confronta problemas de bajos rendimientos relacionados fundamentalmente con la baja fertilidad de los suelos, la sequía y las incidencias de plagas y enfermedades.

A la falta de insumos agroquímicos y energéticos, se suma el limitado acceso que estos productores tienen a nuevos materiales, mejorados o no, que se adapten a las condiciones particulares de la producción agrícola del contexto cubano. Esto se debe a que la capacidad del sistema formal de semillas es limitada para llegar a este sector. Por otro lado, aquellas variedades que llegan a manos de los productores procedentes de este sistema, suelen tener un bajo nivel de adopción debido a que fueron generadas para un comportamiento de adaptación general, y no se ajustan a las necesidades y gustos de los campesinos (Defoer 1998). El sistema formal de semillas es aquel donde los recursos fitogenéticos son manejados por instituciones de investigaciones nacionales, regionales, internacionales e industrias privadas. Este sistema se basa en la capacidad de estas instituciones de seleccionar y multiplicar semillas mejoradas con el fin de obtener un máximo rendimiento con el empleo de altos insumos (Berg 1991, citado por Hardon y Boef 1993).

A pesar del escaso acceso al sistema formal de semillas, los campesinos llevan a cabo su producción conservando, seleccionando e intercambiando variedades, llegándose a tener un flujo de semillas muy dinámico pero relativamente cerrado con relación a la introducción de nuevos materiales (Miranda et al. 2003).

Una alternativa para lograr un acceso eficiente, rápido y sencillo de variedades, ha sido la selección participativa de variedades en ferias de diversidad, en las que cada agricultor elige los materiales de su preferencia, dentro de una amplia gama de materiales que pueden incluir variedades comerciales y precomerciales, líneas mejoradas y variedades criollas (Rios y Wright 2000; Fé et al. 2003). Luego, por medio de la experimentación en finca, los agricultores pueden evaluar el comportamiento de las variedades seleccionadas. De acuerdo con los resultados, algunos agricultores incorporan las nuevas variedades a su producción habitual junto a sus antiguas variedades; otros abandonan algunas o todas sus variedades antiguas (Ortiz et al. 2003).

Si se quiere conocer realmente el impacto de la selección participativa de variedades en una comunidad en particular, es necesario caracterizar su sistema local de semillas y en especial la diversidad genética de sus variedades locales. Los "sistemas locales de semillas" son aquellos en los cuales los campesinos, como principales actores en el manejo de los recursos fitogenéticos, conservan, producen, seleccionan e intercambian semillas, tanto de variedades mejoradas como locales, de diferentes cultivos agrícolas. En estos sistemas las actividades de producción, selección e intercambio de semillas se encuentran integradas a la producción agrícola y a los procesos socioeconómicos de las comunidades campesinas (Almekinders y Louwaars 1999).

Caracterizar la diversidad genética de estos sistemas locales resulta también de utilidad para determinar los caracteres en los que se debe enfatizar en futuros programas de mejora así como para conocer parte de la base genética de la que se dispone para la selección de parentales para dichos programas.

Existen varias alternativas para estimar esta diversidad genética. Tradicionalmente, se han usado para este fin marcadores morfológicos tales como hábito de crecimiento, características de los granos, resistencia a enfermedades y plagas (Singh et al. 1991b). Estos marcadores sin embargo, son afectados por el ambiente y el estado de desarrollo de la planta, tornando menos eficientes sus caracterizaciones (Tatineni et al. 1996).

Con el desarrollo de los marcadores moleculares, se simplificó el estudio de la diversidad genética, pues son independientes de las condiciones ambientales y muestran un alto nivel de polimorfismo, posibilitando una descripción más detallada de la estructura genética de las poblaciones (Williams et al. 1990). Los marcadores RAPD, AFLP, RFLP han sido ampliamente utilizados para medir la diversidad genética dentro y entre especies de microorganismos, animales y plantas, incluyendo el frijol (Tohme et al. 1996; Vasconcelos et al. 1996).

Los marcadores RAPD (amplificación al azar de polimorfismos de ADN) (Williams et al. 1990), se encuentran dentro de los más utilizados en estudios de 
frijol por ser una de las técnicas más sencillas, baratas y por su capacidad en detectar diferencias entre genotipos relacionados.

Los cultivares de frijol suelen dividirse en dos grandes grupos que corresponden a centros primarios de domesticación, ubicados en Mesoamérica y la región sur de Los Andes (Gepts et al. 1986). Estos grupos se definen con base en el tipo de proteína de reserva (Gepts et al. 1986; Gepts y Bliss 1986), variación isoenzimática (Singh et al. 1991a), y el tamaño de las semillas (Singh et al. 1991b), presentando una gran divergencia genética entre los grupos, producto del aislamiento geográfico entre ambas regiones (Rosas 1998). En este sentido, los marcadores RAPD han demostrado su utilidad en separar eficientemente genotipos de frijol de acuerdo con su centro de origen (Nienhuis et al. 1995; Vasconcelos et al. 1996, Franco et al. 1998; Cattan-Toupase et al. 1998; Vera et al. 1999; Duarte et al. 1999b; Beebe et al. 2000; Caixeta y Alves, 2001, Emygdio et al. 2003). Además, los marcadores RAPD pueden ser utilizados para detectar grados de parentesco entre genotipos de frijol (Bai et al. 1998).

El presente estudio tiene como objetivo caracterizar la diversidad genética de los materiales locales de frijol de la comunidad El Tejar- La Jocuma, Municipio de La Palma, Pinar del Río, Cuba, por medio de marcadores RAPD y morfológico-agronómicos.

\section{MATERIALES Y MÉTODOS}

\section{Colecta de las accesiones representativas de frijol en la comunidad}

Las fincas donde se manejaba una diversidad representativa de frijol de la comunidad El Tejar- La Jocuma, Municipio La Palma, Pinar del Río, se identificaron como parte de la caracterización del sistema local de semillas de frijol de dicha comunidad (Miranda et al. 2003). Para esto se realizaron encuestas y visitas a las parcelas de 23 campesinos dueños de fincas, que representan el $47 \%$ de las fincas de la comunidad. A partir de esto, se colectaron 27 accesiones representativas de la diversidad local de la comunidad, cultivadas en nueve fincas pertenecientes a los agricultores líderes en el manejo y diseminación de semillas de la comunidad. También se incluyeron aquellos que manejaban más de tres variedades.

De las 27 accesiones, 13 son de grano negro, seis de grano rojo, cinco de grano bayo y tres de grano blanco.

Tres accesiones se caracterizaron por una gran heterogeneidad en cuanto a tamaño y color de la semilla, y fueron separadas en subtipos por los campesinos de acuerdo con estas diferencias en apariencia de la semilla. En los tres casos existía un subtipo predominante que representaba entre el $62 \%$ y $76 \%$ de los granos. Este subtipo predominante fue considerado como la accesión en sí. En el caso del resto de los subtipos, solo se tomaron para el estudio, aquellos que superaban el $14 \%$ de los granos y se excluyeron los que quedaban por debajo. Estos subtipos se incluyeron en el análisis como si fueran nuevas accesiones para compararlos con el subtipo predominante. De acuerdo con esto, la accesión $\mathrm{R}(\mathrm{C})$, de granos color rojo, tiene dos subtipos de color rojo también que fueron incluidos en el estudio (R1(C) y R2(C)), de la accesión By(P) de granos color bayo se incluyó un subtipo de color bayo (By1(P)) y de la accesión By $(\mathrm{G})$ de grano color bayo, también se incluyó un subtipo de grano color bayo (By1(G)).

\section{Caracterización morfológica y agronómica}

Se realizó una caracterización morfo-agronómica de 26 de las 27 colectas y de los subtipos incluidos en el estudio. La accesión faltante fue la N60(B), que no estuvo disponible por problemas de germinación.

Se evaluaron caracteres cuantitativos y cualitativos. Los cuantitativos fueron el número de semillas por vaina (NSV), número de vainas por planta (NVP), número de nudos en el tallo principal (NNP), número de racimos por planta (NRP), peso de cien semillas (PCS), número de semillas por vaina (NSV), número de vainas por racimo (NVR), rendimiento por parcela (RP) y días a la floración (DF). Los caracteres cualitativos evaluados fueron el color de la testa de la semilla (CT), presencia/ausencia de guías (PRG) y color de las flores (CF) y tamaño de las semillas (TS). Los caracteres evaluados fueron seleccionados entre los que contribuyen a la caracterización de la diversidad genética en frijol, según Castiñeiras et al. (1991). 
El color de la testa se evaluó según la tabla para la clasificación de tonalidades de granos de frijol, propuesta por Voysest (2000). El tamaño de los granos se determinó según lo propuesto por Singh et al. (1991b), quienes clasificaron los granos, de acuerdo al peso de 100 semillas (PSC), en pequeñas (PCS menor que 25 $\mathrm{g}$ ), medianas (PCS mayor que $25 \mathrm{~g}$ y menor de $40 \mathrm{~g}$ ) y grandes (PCS mayor que $40 \mathrm{~g}$ ). El resto de los caracteres fueron evaluados de acuerdo con el descriptor varietal para frijol desarrollado por Muñoz et al. (1993).

Las evaluaciones se realizaron en 10 plantas por accesión. La siembra de dichas accesiones se realizó en enero del 2003 con una densidad aproximada de 250.000 plantas por hectárea y empleando un diseño ampliado modificado (Lin et al. 1983). El experimento se ubicó físicamente en los terrenos experimentales de la Estación Experimental "Las Papas", perteneciente al Instituto Nacional de Ciencias Agrícolas, La Habana, Cuba. Esta estación se encuentra a $138 \mathrm{msnm}$ y sus terrenos tienen una topografía plana con suelos clasificados como ferralítico rojo compactado, sobre caliza profunda, con una fertilidad de media a alta (Hernández et al. 1999).

Para el procesamiento de los datos se realizaron análisis multivariados a partir de los caracteres cuantitativos evaluados. Específicamente se realizaron un análisis de componentes principales, un análisis de conglomerados (cluster) y un análisis discriminante usando el programa estadístico SPSS 11. El análisis de conglomerados se realizó utilizando el índice de la distancia euclidiana, para agrupar las accesiones en función de todos los caracteres cuantitativos evaluados. El análisis de componentes principales permitió determinar los caracteres que más contribuían a la formación de los grupos. El análisis discriminante fue realizado para verificar el agrupamiento formado por el análisis de conglomerados. Los caracteres cualitativos no fueron incluidos en los análisis multivariados, pero sin embargo, brindaron información adicional que ayudó en el análisis de los resultados.

\section{Marcadores RAPD}

Se utilizaron marcadores RAPD para el estudio de la diversidad genética de las 27 colectas y de los subtipos incluidos en el estudio. El ADN genómico total fue extraído de las hojas trifoliadas de ocho plántulas 15 días después de la germinación, según el método CTAB (bromuro de cetilmetilamonio) empleado en el Laboratorio de Biotecnología de la Escuela Agrícola Panamericana Zamorano, Honduras, basado en el método propuesto por Skroch et al. 1998). La concentración de las muestras de ADN, se determinó usando un fluorómetro de DNA (Hoefer Pharmacia Biotech Inc.).

Las reacciones de amplificación se realizaron en un termociclador (PCR-100 TM, Programable Termal Controller, Peltier-Effect Cycling), luego de realizar la dilución del DNA hasta una concentración de $4 \mathrm{ng} / \mu \mathrm{l}$. Para las reacciones de amplificación se utilizaron 15 cebadores (decámeros) de Operon Technologies, los cuales fueron seleccionaron para este trabajo por haber sido citados en la literatura como exitosos en generar bandas polimórficas en el cultivo del frijol (Alzate-Marin et al. 2003; Duarte et al. 1999b; Metails et al. 2000, Skroch et al. 1998 y Emygdio et al. 2003). Los decámeros utilizados fueron OP-A2, OP-B15, OP-C4, OP-D8, OP-G5, OP-I16, OP-I6, OP-L4, OP-P9, OP-Q9, OPT7, OP-U1, OP-U19, OP-W6 y OP-X1. Las reacciones de amplificación se realizaron en un volumen de total de $20 \mu \mathrm{l}$ por cada muestra, de la mezcla de $10 \mu \mathrm{l}$ de DNA (4 ng/ $\mu \mathrm{l}), 4,44 \mu \mathrm{l}$ de agua, 4,40 de buffer Tris-HCl (250 mM, pH 8,5), 0,8 $\mu \mathrm{l}$ de sln de $\operatorname{dNTP}(10 \mathrm{mM})+$ $\mathrm{MgCl}_{2}(25 \mathrm{mM}), 0,8$ del cebador $(10 \mu \mathrm{l}), 0,7 \mu \mathrm{l}$ de Taqpolimerasa $(5 \mathrm{U} / \mu \mathrm{l})$ y $10 \mu \mathrm{l}$ de $\mathrm{ADN}(4 \mathrm{ng} / \mu \mathrm{l})$. El perfil térmico utilizado para la amplificación de los fragmentos RAPD fue un paso inicial dos ciclos de desnaturalización a $91^{\circ} \mathrm{C}$ por $60 \mathrm{seg}$, de acoplamiento a $42^{\circ} \mathrm{C}$ por $15 \mathrm{seg}$ y de elongación a $72^{\circ} \mathrm{C}$ por $70 \mathrm{seg}$, seguido por un segundo paso de 38 ciclos de desnaturalización a $91^{\circ} \mathrm{C}$ por $15 \mathrm{seg}$, de acoplamiento a $42^{\circ} \mathrm{C}$ por $15 \mathrm{seg}$ y de elongación a $72^{\circ} \mathrm{C}$ por $70 \mathrm{seg}$ y un tercer paso consistente en una elongación final a 72 ${ }^{\circ} \mathrm{C}$ por 4 min durante un único ciclo.

Los productos de la amplificación fueron separados en un tanque de electroforesis (EC Maxicell EC $360 \mathrm{M}, 22$ pozos) a $140 \mathrm{~V}$ por 60 minutos, en un gel de agarosa al $1 \%$, con bromuro de etilo. Una escalera de ADN de 100 pb se utilizó como patrón de peso molecular de los respectivos fragmentos de ADN amplificados, los cuales fueron visualizados y fotografiados sobre una fuente de luz UV (Fotodyne UV26).

Las bandas polimórficas generadas se clasificaron visualmente en fuertes, regulares y dudosas de acuerdo con la resolución y a su intensidad. Solo se tomaron 
en cuenta las bandas intensas y regulares para el análisis y fueron desestimadas aquellas que resultaron muy tenues o dudosas. Para el procesamiento de los datos se construyó una matriz de datos binarios basada en la presencia (1) o ausencia (0) de cada fragmento específico polimórfico de ADN amplificado, generado por los 15 cebadores utilizados para cada variedad. Se empleó el programa de computación NTSYS, a través del cual se calcularon los valores de similitud de Dice (Dice 1945) a partir de los cuales se elaboró la matriz para agrupar los cultivares, utilizando el método UPGMA. El índice de Dice se seleccionó porque dentro de los índices de similitud descritos es uno de los más adecuados para el estudio de divergencia genética entre genotipos de frijol analizados por medio de marcadores RAPD, por revelar una mayor eficiencia, menores distorsiones y estrés y mejores correlaciones, además de ser capaz de agrupar los cultivares de frijol según sus respectivos centros de origen (Emygdio et al 2003; Duarte et al. 1999a; Marti et al. 2003).

\section{RESULTADOS}

\section{Marcadores morfológicos y agronómicos}

La evaluación de los caracteres morfo-agronómicos cualitativos indicó que de los 27 genotipos, 12 tuvieron el grano color negro, siete de color rojo (con tonalidades de rosado, café rojizo y púrpura), tres de color blanco y siete moteadas, éstas últimas con tres combinaciones de colores primarios y secundarios (púrpura y crema suave, crema suave y púrpura y rosado y púrpura). También las flores presentaron diferentes tonalidades, encontrándose accesiones con flores de color lila, rosado, blanco y blanco con el estandarte con rayas moradas. En relación con el hábito de crecimiento, hubo accesiones con hábito determinado e indeterminado.

Dentro de las accesiones de grano negro predominó el hábito indeterminado, pues, con excepción de una, mostraban la presencia de guías largas. Estas accesiones se caracterizaron por mostrar flores de color lila, lo que es característico de los materiales de grano negro. En las accesiones de color bayo y rojo, se observó una mayor diversidad en el hábito de crecimiento, no así en el color de las flores, pues se observaron flores rosadas para todas las accesiones de grano moteado y flores blancas con el estandarte morado, para todas las de grano rojo a excepción de una (Cuadro 1).

En general, las accesiones de semillas pequeñas de color rojo o negro resultaron ser más abundantes, lo que de acuerdo con Castiñeiras et al. 1991, caracteriza a las variedades locales cubanas de frijol. En este estudio en particular sin embargo, prevalecieron sobre todo las accesiones de grano negro y pequeño. Esto, de acuerdo con los mismos autores, es característico de las provincias occidentales de la Isla de Cuba, dentro de las que se encuentra Pinar del Río, provincia a la que pertenece la comunidad donde se colectaron las accesiones del presente estudio.

Por su parte, el análisis de los caracteres cuantitativos evaluados, generó un dendograma construido a partir de las distancias euclidianas con dos niveles de truncadura para el análisis (Figura 1). El primer nivel de truncadura (a un valor de 9) permite la formación de dos grupos muy alejados genéticamente entre sí, designados en el clúster con las letras A y $\mathrm{B}$. La variedad $B y(R)$ no se encuentra formando parte de ningún grupo, aunque se relaciona más con el grupo B. Considerando un nivel de truncadura menor (de aproximadamente 6,4), se forman cinco grupos, G1, G2, G3, G4 y G5. A este nivel de truncadura los genotipos $(\mathrm{By}(\mathrm{R})$ $\mathrm{N} 60(\mathrm{~V})$ y N60(S), quedaron agrupados independientemente de los cinco grupos formados. Sendos análisis de discriminante permitieron verificar la precisión del agrupamiento de todos los grupos para ambos niveles de truncadura.

En la Figura 2 se muestra un análisis multivariado de componentes principales para los genotipos de acuerdo a los caracteres cuantitativos evaluados. Los coeficientes de correlación entre caracteres incluidos en el análisis y los dos primeros componentes principales, así como los valores propios, miden la importancia de cada uno de los componentes en términos de varianza absoluta (Cuadro 2). Cabe señalar que en el análisis de componentes principales solo se consideraron los primeros dos por tener valores mayores que uno, de acuerdo al procedimiento propuesto por Kaiser (1960). Los componentes elegidos explicaron el $76,8 \%$ de la variación total, a la cual el primer componente (C1) contribuyó en un 54,30\% y el segundo (C2) en un $22,52 \%$. 
Cuadro 1. Caracteres cualitativos de colectas de frijol obtenidas en la comunidad de El Tejar-La Jocuma, Municipio de Pinar del Río, Cuba. Evaluación realizada en la Estación Experimental "Las Papas". Cuba, 2003.

\begin{tabular}{|c|c|c|c|c|c|}
\hline & $\begin{array}{c}\text { Tamaño } \\
\text { de semilla }\end{array}$ & $\begin{array}{l}\text { Color primario } \\
\text { de la semilla }\end{array}$ & $\begin{array}{l}\text { Color secundario } \\
\text { de la semilla }\end{array}$ & $\begin{array}{l}\text { Color del } \\
\text { estandarte de } \\
\text { las flores }\end{array}$ & $\begin{array}{l}\text { Hábito de } \\
\text { crecimiento }\end{array}$ \\
\hline $\operatorname{Nvm}(\mathrm{C})$ & pequeño & negro & - & lila & indeterminado \\
\hline $\mathrm{R}(\mathrm{A})$ & pequeño & café rojizo & - & blanca* & indeterminado \\
\hline $\operatorname{Nvm}(P)$ & pequeño & negro & - & lila & indeterminado \\
\hline $\mathrm{R} 1(\mathrm{C})$ & pequeño & rosado & - & blanca* & determinado \\
\hline $\mathrm{R}(\mathrm{C})$ & pequeño & rosado & - & blanca* & determinado \\
\hline $\mathrm{B}(\mathrm{R})$ & pequeño & blanco & - & blanca & determinado \\
\hline $\mathrm{B}(\mathrm{B})$ & pequeño & blanco & - & blanca & indeterminado \\
\hline $\mathrm{R}(\mathrm{P})$ & pequeño & púrpura & - & blanca* & indeterminado \\
\hline $\mathrm{R}(\mathrm{S})$ & pequeño & café rojizo & - & blanca* & indeterminado \\
\hline $\mathrm{B}(\mathrm{V})$ & pequeño & blanco & - & blanca & indeterminado \\
\hline N60(B) & pequeño & negro & - & lila & indeterminado \\
\hline N60(M) & pequeño & negro & - & lila & indeterminado \\
\hline N60(P) & pequeño & negro & - & lila & indeterminado \\
\hline $\operatorname{Nvm}(G)$ & pequeño & negro & - & lila & indeterminado \\
\hline $\mathrm{Nvb}(\mathrm{G})$ & pequeño & negro & - & lila & indeterminado \\
\hline N60(A) & pequeño & negro & - & lila & indeterminado \\
\hline $\mathrm{N} 60(\mathrm{G})$ & pequeño & negro & - & lila & indeterminado \\
\hline N90(A) & pequeño & negro & - & lila & indeterminado \\
\hline N60(V) & pequeño & negro & - & lila & indeterminado \\
\hline N60(S) & pequeño & negro & - & lila & determinado \\
\hline $\mathrm{R} 2(\mathrm{C})$ & mediana & rosado & - & rosada & determinado \\
\hline By1(P) & mediana & púrpura & crema suave & rosada & indeterminado \\
\hline $\mathrm{By}(\mathrm{G})$ & mediana & púrpura & crema suave & rosada & determinado \\
\hline $\mathrm{ByO}(\mathrm{B})$ & mediana & café rojizo & crema suave & rosada & determinado \\
\hline $\mathrm{R}(\mathrm{B})$ & mediana & rosado & - & blanca* & determinado \\
\hline $\operatorname{By} 1(G)$ & grande & púrpura & crema suave & rosada & determinado \\
\hline $\mathrm{ByC}(\mathrm{B})$ & grande & crema suave & púrpura & rosada & determinado \\
\hline $\mathrm{By}(\mathrm{P})$ & mediana & púrpura & crema suave & rosada & indeterminado \\
\hline $\mathrm{By}(\mathrm{R})$ & mediana & rosado & púrpura & rosada & indeterminado \\
\hline
\end{tabular}

* estandarte con rayas moradas.

Cuanto mayor es el valor absoluto del coeficiente de correlación, mayor es la contribución de la variable para la formación del componente principal. Considerando esto, el presente análisis permitió identificar los caracteres que más contribuyen al agrupamiento de las accesiones estudiadas al identificar los caracteres que más influyen en cada componente, de acuerdo con los valores mostrados en el Cuadro 2, siendo para el primer componente el peso de 100 semillas (PCS), el número de racimos por planta (NRP), el número de nudos del tallo principal (NNP), el número de semillas por planta (NSP), número de vainas por planta (NVP) y el rendimiento por planta (RP). En el segundo componente, se destacaron el número de vainas por racimo (NVR) y los días a la floración (DF). De acuerdo con esto, se pueden identificar y destacar en la gráfica de dispersión de las accesiones estudiadas los grupos obtenidos previamente en el análisis de conglomerados, lo que permite identificar los caracteres cuantitativos que más influyen en el agrupamiento y las características que distinguen a cada grupo.

De acuerdo con lo anterior, se puede observar que los grupos A y B y G1, G2, G3, G5 y G5 en la 


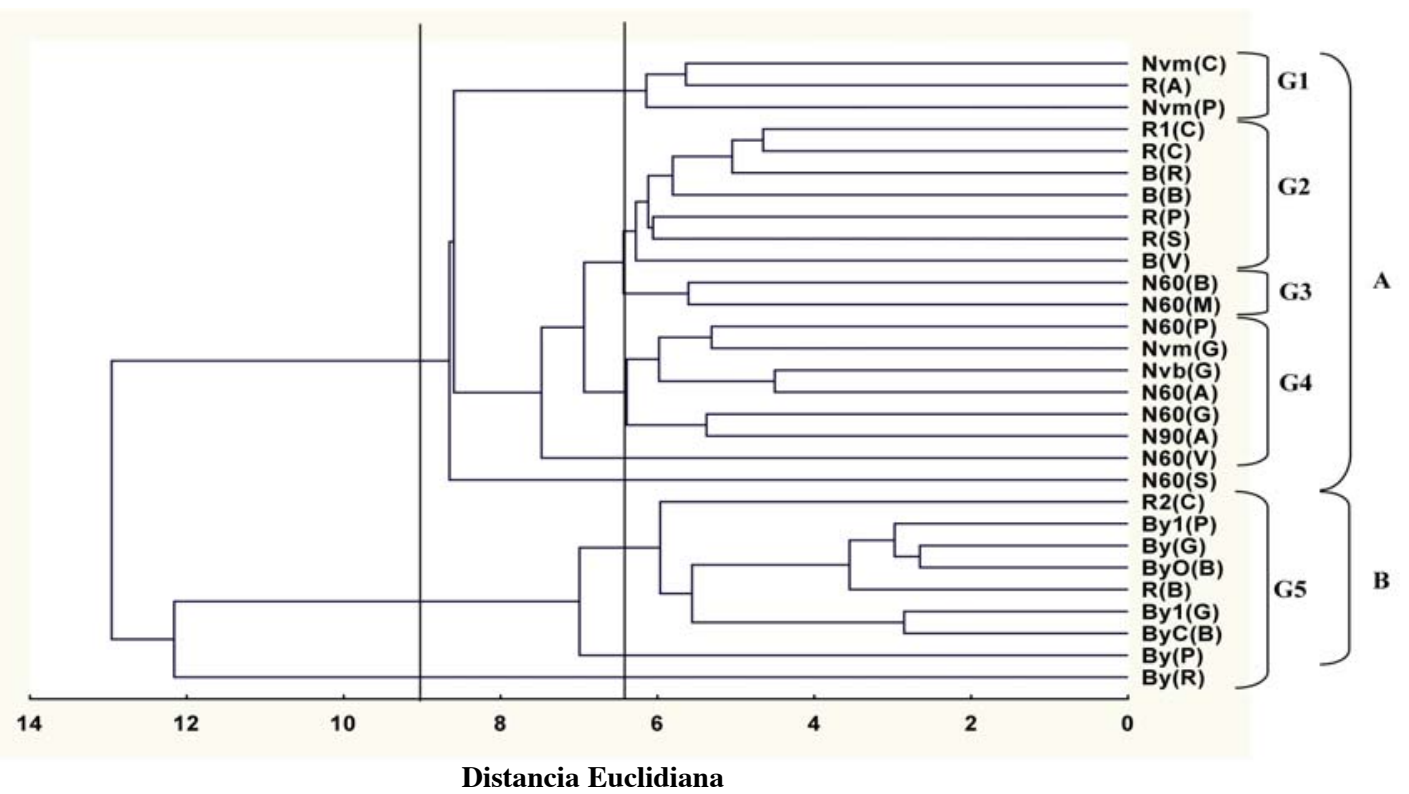

Figura 1. Dendrograma para caracteres morfológicos de 27 colectas de frijol obtenidas con base en las distancias euclidianas. Evaluación agronómica realizada en la Estación Experimental “Las Papas”, La Habana, Cuba. 2003.

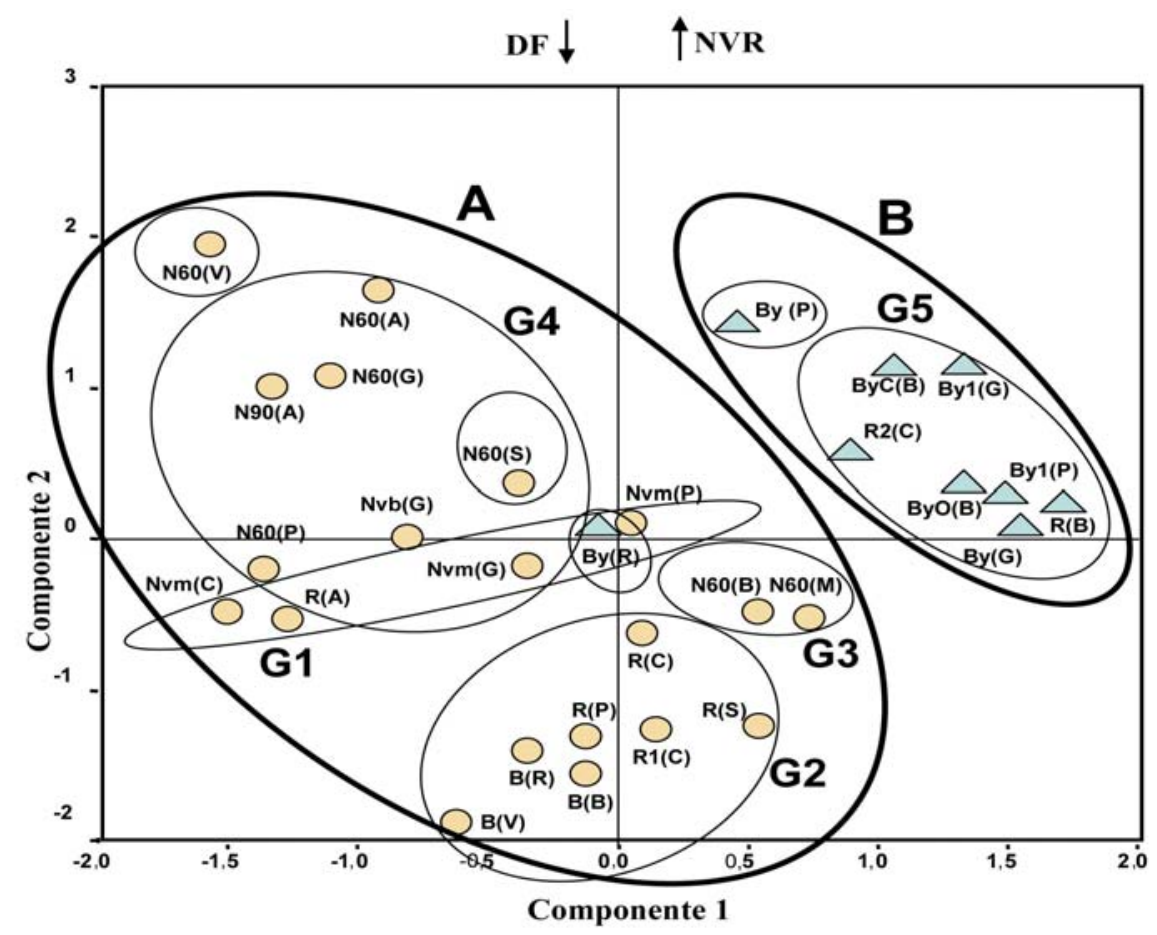

Figura 2. Dispersión de las accesiones de frijol (Phaseolus vulgaris L.) en los dos primeros componentes principales (las accesiones ubicadas en el grupo A del cluster, se representan con círculos y las ubicadas en el grupo B con triángulos). Evaluación agronómica realizada en la Estación Experimental "Las Papas”, La Habana, Cuba. 2003. 
Cuadro 2. Contribución relativa de los caracteres cuantitativos evaluados a los dos primeros componentes. Cuba, 2003.

\begin{tabular}{|c|c|c|c|c|c|c|c|c|c|c|c|c|}
\hline & \multirow{2}{*}{$\begin{array}{l}\text { Valor } \\
\text { propio }\end{array}$} & \multirow{2}{*}{$\begin{array}{l}\text { Porcentaje } \\
\text { de variación }\end{array}$} & \multirow{2}{*}{$\begin{array}{l}\text { Porcentaje } \\
\text { de variación } \\
\text { acumulado }\end{array}$} & \multicolumn{9}{|c|}{ Importancia relativa de los caracteres } \\
\hline & & & & PCS & NRP & NNP & NSV & NSP & NVP & NVR & $\mathbf{R P}$ & DF \\
\hline $\mathrm{C} 1$ & 4.887 & 54,30 & 54,30 & $\underline{0.724}$ & -0.905 & -0.813 & $-0,570$ & $\underline{-0.945}$ & $\underline{-0.915}$ & $-0,269$ & -0.711 & $-0,501$ \\
\hline $\mathrm{C} 2$ & 2.032 & 22,57 & 76,88 & 0,479 & $-0,157$ & $-0,309$ & 0,103 & 0,251 & 0,249 & $\underline{0.788}$ & 0,558 & $\underline{-0.783}$ \\
\hline
\end{tabular}

representación del análisis de componentes principales se encuentran bien definidos y separados, lo que permite realizar un análisis de las características que los distinguen.

El grupo B está formado por 8 accesiones de granos medianos o grandes y de color moteado o rojo y prevalecen los materiales con flores rosadas y hábito de crecimiento determinado. En el análisis de componentes principales, los genotipos pertenecientes a este grupo se encuentran concentrados en el cuadrante superior derecho, donde en este análisis en particular se ubican las accesiones con los mayores valores de peso de cien semillas (PCS) y los menores valores de los caracteres que constituyen componentes del rendimiento (el número de racimos por planta (NRP), el número de semillas por planta (NSP), número de vainas por planta (NVP) y el rendimiento por planta (RP)), a excepción de número de vainas por racimo (NVR). Este grupo también se caracteriza por contener accesiones con menores valores de número de nudos del tallo principal (NNP) característicos de materiales con hábito determinado y mayores valores de días a la floración (DF).

El grupo B tiene una diversidad relativamente baja entre de las accesiones que lo componen, considerando que estas presentan muchas características cualitativas comunes y que no se encuentran dispersas en el gráfico. Esto se aprecia cuando a un nivel de truncadura menor en el análisis de conglomerados, este grupo no se subdivide en grupos más pequeños, sino por el contrario, la mayoría de las accesiones continúan formando un solo grupo, el G5. Solo la accesión $\mathrm{By}(\mathrm{P})$ queda separada de las demás y se distingue de acuerdo con su ubicación en el análisis de componentes principales por valores relativamente menores de peso de cien semillas (PCS) y mayores de caracteres que constituyen componentes del rendimiento, así como del número de nudos del tallo principal (NNP), probablemente por ser la única de hábito indeterminado ubicada en el grupo B.

El grupo A, por su parte, está formado por 20 accesiones, dentro de las cuales se encuentran todas las de grano negro, blanco y la mayoría de las de grano rojo. Este es un grupo muy diverso en relación a los caracteres cualitativos evaluados como el hábito de crecimiento y el color de las flores, pero muy uniforme en cuanto al tamaño de los granos, pequeños en todos los casos. En el análisis de componentes principales, las accesiones pertenecientes a este grupo no se ubican agrupadas en ningún cuadrante en particular, sino que se encuentran distribuidas en los dos cuadrantes izquierdos y en menor medida por el inferior derecho, denotándose una mayor diversidad que la observada en el grupo B en relación a los caracteres cuantitativos evaluados. Esta mayor diversidad se evidencia en el análisis de conglomerado con la formación dentro del grupo A, a un nivel de truncadura menor, de cuatro grupos separados y bien definidos y en la separación de tres accesiones que a este nivel no pertenecen a ninguno de estos grupos.

Estos cuatro grupos en la representación de componentes principales aparecen diferenciados y con características propias El grupo G1 está formado por tres genotipos, dos de granos negros y uno de granos rojos. Estos genotipos tienen en común un hábito de crecimiento indeterminado y presentan valores medios de días a la floración (DF) y número de vainas por racimo (NVR) y a excepción de la acepción Nvm(P), valores altos de los caracteres que constituyen componentes de rendimiento. El grupo G2 está formado por siete genotipos, de los que forman parte todos los de granos blancos analizados y la mayoría de los de granos rojos pequeños, sin que aparezca incluido ningún genotipo con grano de otro color. En este grupo, las accesiones se 
caracterizan por presentar flores blancas, hábito de crecimiento tanto determinado como indeterminado, valores altos de días a la floración (DF) y bajos de número de vainas por racimo (NVR). Los grupos G3 y G4 por su parte, presentan dos y siete genotipos respectivamente, todas caracterizados por presentar granos negros flores lilas y hábito de crecimiento indeterminado. Estos grupos tienen menores valores de días a la floración y mayores de de número de vainas por racimo (NVR) que el grupo G2 y se distinguen entre si por los valores de peso de cien semillas (PCS) (mayores para el grupo G3 que para el grupo G4) y de los caracteres que constituyen componentes del rendimiento (menores para el grupo G3 que para el grupo G4).

En general, de acuerdo al análisis de conglomerado y de componentes principales a partir de las evaluaciones morfo agronómicas, se puede afirmar que los genotipos estudiados se separan en dos grandes grupos bien definidos y alejados genéticamente, que se distinguen fundamentalmente por el tamaño de los granos, caracteres asociados al rendimiento y en menor medida color de los granos. En relación al tamaño de los granos, este ha sido reportado por diversos autores como uno de los principales caracteres en la discriminación de los cultivares en los acervos genéticos mesoamericano y andino (Singh et al. 1999; Voysest y Dessert 1991). De acuerdo a este criterio, los grupos A y B que se observan en el clúster, podrían estar conformados por accesiones pertenecientes a los reservorios mesoamericano (grupo A) y andino (grupo B). Es importante destacar que en el grupo B, que de acuerdo al análisis anterior pertenece al reservorio andino, aparecen tanto genotipos de grano grande como de grano mediano y estos últimos podrían estar ubicados tanto dentro del grupo mesoamericano, como del andino, de acuerdo a la clasificación de Singh et al. (1991b) y Singh (2001). No obstante, los materiales de tamaño mediano de este estudio en particular podrían pertenecer exclusivamente al reservorio andino, considerando que se han reportado en la literatura genotipos medianos con valores de peso de 100 semillas cercanos a 40 gramos y que se han clasificado como pertenecientes al reservorio andino (Voysest 2000), lo que resulta característico de los genotipos de frijol de origen andino colectados en el Caribe (Blair 20054). Este grupo

4 BLAIR, M. 2005. Comunicación personal. Centro Internacional de Agricultura Tropical (CIAT). Colombia además presenta otras características que lo distinguen y que apoyan su clasificación. Estas son: menores valores de días a la floración, menor cantidad racimos por planta, de vainas por planta y de nudos en el tallo principal, flores menos pigmentadas y una alta prevalencia de hábito determinado de crecimiento. Estas características coinciden con las de las accesiones cubanas estudiadas por Castiñeiras et al. (1994) y que ellos clasificaron como pertenecientes al acervo andino por presentar faseolinas tipo $\mathrm{T}$, un marcador confiable de este centro de origen.

La accesión $\mathrm{By}(\mathrm{R})$, por último, no aparece ubicada en ninguno de los dos grupos principales (A y B) y aunque se encuentra más relacionada en el dendograma con el grupo B, presenta características particulares que lo ubican en el análisis de componentes principales muy relacionado con el grupo A, por lo que podría tratarse de un híbrido entre materiales de los dos centros de origen. Este tipo de materiales, que se encuentran con cierta frecuencia en el Caribe, tienen a menudo tamaños de semillas intermedios entre los tipos andinos y mesoamericanos, así como diferencias en el hábito de crecimiento y otros caracteres morfológicos (Durán et al. 2005), lo que coincide con este caso. Esta hibridación o introgresión sin embargo, no puede ser demostrada sin el uso de marcadores codominantes.

\section{Marcadores RAPD}

Los 15 cebadores generaron 31 bandas polimórficas confiables con una amplitud de variación entre uno y tres bandas por cebador y una media de 2,07 bandas por cebador. El nivel de polimorfismos generado por estos cebadores es bajo en relación a los obtenidos por otros autores (Alzate-Marin et al. 2003; Duarte et al. 1999b; Metails et al. 2000; Skroch et al. 1998; Emygdio et al. 2003). Esto se debe a que el nivel de polimorfismo no solo depende de los cebadores que se utilicen; sino además de la proporción de bandas polimórficas que puedan considerarse confiables en el estudio en particular y del nivel de divergencia entre los genotipos estudiados (Duarte et al. 1999b).

El análisis de agrupamiento por el método UPGMA generó un dendograma construido a partir de los valores del índice de similaridad de Dice, con dos niveles de truncadura para el análisis, que arrojaron 


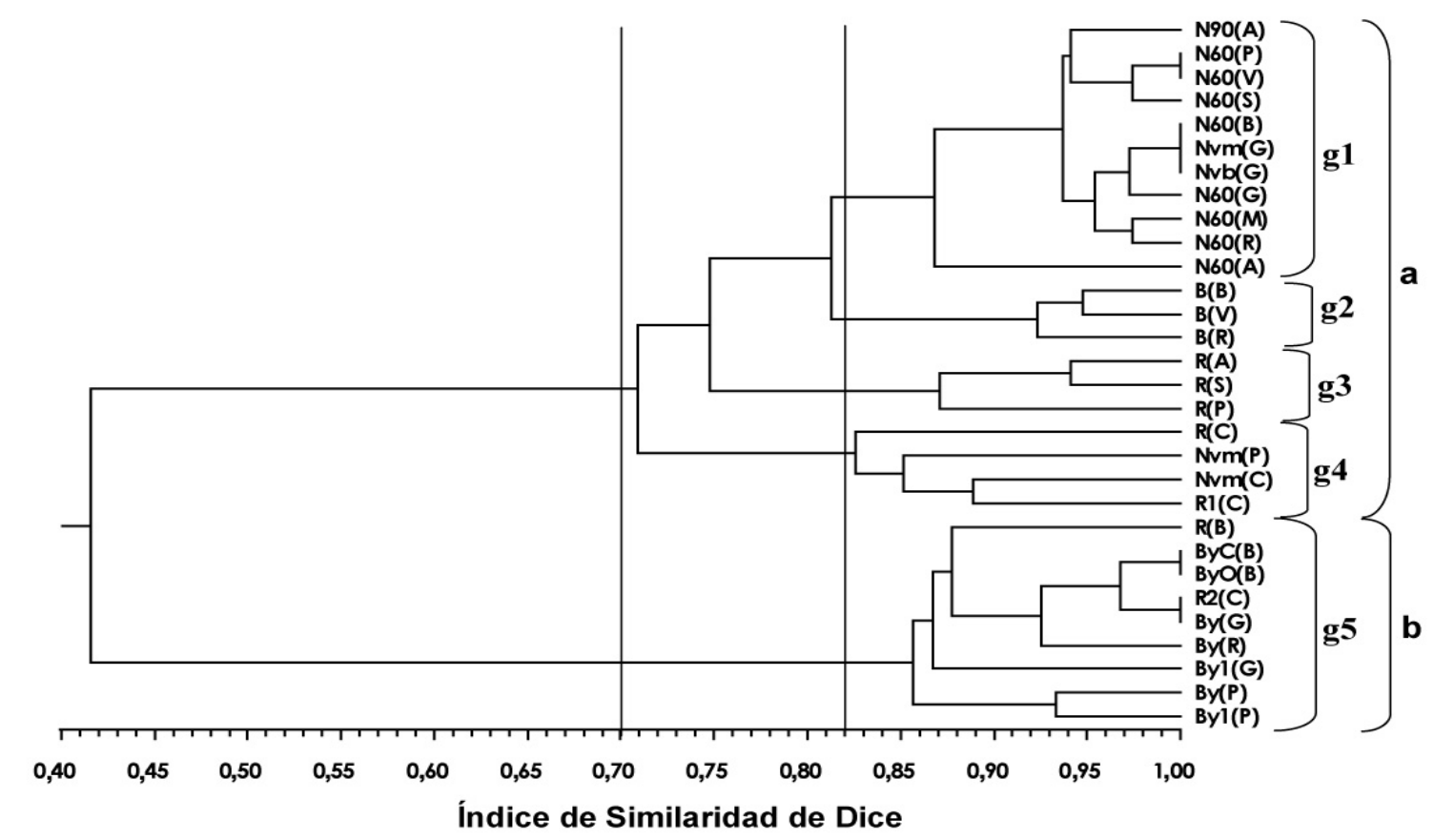

Figura 3. Dendograma de accesiones de frijol común (Phaseolus vulgaris L.) basado en datos de marcadores RAPD usando UPGMA. Marcadores RAPD empleados fueron evaluados en la Escuela Agrícola Panamericana, El Zamorano. 2003.

resultados similares a los observados por medio de marcadores morfoagronómicos. Al primer nivel de truncadura (a un valor de 0,7 ) los genotipos estudiados se separan en dos grupos principales bien definidos "a" y "b". Considerando un valor de truncadura mayor $(0,82)$, se forman cinco grupos, g1, g2, g3, g4 y g5 (Figura 3$)$.

Los grupos "a" y "b" corresponden respectivamente en cuanto a su composición con los grupos A y B del análisis de conglomerados realizado a partir de los caracteres morfo-agronómicos, con la única diferencia de que el genotipo $\mathrm{By}(\mathrm{R})$ forma parte del grupo "b" y no del B. Estos grupos presentan un índice de similaridad entre ellos muy bajo $(0,41)$, corroborando que ambos grupos se encuentran alejados genéticamente entre si, lo que junto a las características morfoagronómicas que distinguen cada grupo, apoya la hipótesis de que ambos grupos representan los acervos mesoamericano y andino respectivamente. Estos resultados son similares a los encontrados por otros autores, quienes han demostrado que los marcadores RAPD son efectivos en la separación de las variedades de acuerdo a su centro de domesticación (Nienhuis et al. 1995; Vasconcelos et al. 1996, Franco et al. 1998; Cattan-Toupase et al. 1998; Vera et al. 1999; Duarte et al. 1999b; Beebe et al. 2000; Caixeta y Alves 2001, Emygdio et al. 2003).

Del mismo modo, al igual que en los resultados obtenidos por medio de los marcadores morfo agronómi$\cos$, las accesiones pertenecientes al acerco andino (grupo "b") presentan menor diversidad genética entre ellas que las que pertenecen al acervo mesoamericano (grupo "a"). Esto se evidencia cuando el análisis de conglomerados se realiza a un nivel mayor de truncadura $(0,83)$, y se forman cuatro grupos bien diferenciados (g1, g2, g3 y g4) dentro del grupo "a" (acervo mesoamericano) y solo uno en el grupo "b" (g5) (Figura 3).

Los grupos formados dentro del grupo "a" (g1, g2, g3 y 4), sin embargo, no corresponden exactamente con los del grupo A del clúster derivado del análisis con los caracteres morfo-agronómicos, aunque existe cierto nivel de correspondencia entre algunos de estos. El grupo g1 presenta solo accesiones de granos de 
color negro y agrupa exactamente aquellas variedades que forman parte de los grupos G3 y G4 del conglomerado elaborado con los datos morfoagronómicos, a excepción de las accesiones N60(V) y N60(S), que en este último análisis no se ubican en ningún grupo. El grupo g2, por su parte, contiene todas las accesiones de granos blancos del estudio, mientras que el grupo g3 contiene la mayoría de las accesiones de granos rojos. Estos dos grupos, el g2 y el g3, están formados en su conjunto mayormente por aquellas accesiones que conforma el grupo G2 del conglomerado elaborado con los datos morfoagronómicos. El grupo g5 por último, presenta entre sus accesiones los genotipos $\operatorname{Nvm}(C)$ y $\operatorname{Nvm}(P)$, que son las únicas de grano negro que se encuentran separadas de las variedades con grano de ese color para ambos análisis de conglomerados. En general, a pesar del cierto nivel de correspondencia que existe entre los grupos formados por medio de los análisis de conglomerados con marcadores morfo agronómicos y moleculares, se puede observar que en el caso de los marcadores RAPD, las accesiones del grupo mesoamericano tienden a agruparse en mayor medida de acuerdo al color de los granos. Así, el grupo g1 agrupa solo accesiones de granos negros, el grupo g2 las de granos blancos, el grupo g3 agrupa solo accesiones de granos rojos, y el grupo g4, que es una excepción, incluye accesiones de granos rojos y negros. Esta tendencia a agrupar los genotipos de acuerdo a su color del grano coincide con lo descrito por Beebe et al. (1995) y Duarte et al. (1999a), quienes encontraron que las variedades de la raza mesoamericana tienden a subdividirse de acuerdo al color de la testa del grano. Beebe et al. (1995) confirmaron que las líneas mejoradas y los cultivares de frijol común de testa roja y negra constituyen distintas poblaciones cuando se analizaron usando marcadores RAPD. Estos autores concluyeron que la selección de genes para color de semillas ha cubierto una considerable parte del genoma por ligamiento, lo cual causa que los cultivares con el mismo color de semilla estén más relacionados dentro de determinado grupo.

La presencia de accesiones pertenecientes a los grupos mesoamericanos y andinos en las poblaciones de frijol común en el Caribe se corresponde con los hallazgos realizados por Durán et al. (2005), quienes realizaron estudios de diversidad genética de frijol común para accesiones caribeñas por medio de marcadores morfoagronómicos y moleculares (RAPD y faseolinas). Estos resultados coincidieron con los

ISSN: 1021-7444 encontrados por Castiñeiras et al. (1991 y 1994), quienes además hallaron que las accesiones pertenecientes al grupo mesoamericano se encuentran presentes en mayor proporción en la poblaciones cubanas que las pertenecientes al acervo andino. Estos autores plantearon, de acuerdo con estos y otros resultados, la teoría de que la ruta de introducción de frijol en Cuba debió ser a través del arco de las Antillas, en un período posterior a la confluencia de los cultivares procedentes de los dos centros mayores de domesticación de este cultivo en la zona norte de América del sur, o que pudo haber llegado independientemente de estos dos centros por la misma ruta.

Aunque algunas de las accesiones incluidas en el estudio y reportadas como diferentes por los agricultores, son en realidad muy similares desde el punto de vista genético (100\% en el índice de similaridad de Dice), se puede afirmar que en general la diversidad genética de las accesiones incluidas en este estudio es relativamente alta, estando representados ambos acervos primarios de domesticación del frijol, el mesoamericano y el andino, lo que hace que las accesiones se dividan en primera instancia en dos grupos muy alejados genéticamente entre si. Además, existe diversidad dentro de cada uno de estos dos grupos, fundamentalmente en el mesoamericano, lo que se denota por la formación de grupos bien definidos con características morfo agronómicas propias que los distinguen.

Este nivel de diversidad, aunque no es extraordinario, podría clasificarse como notable si se considera que están representadas en el estudio solamente las variedades locales de una comunidad y que Cuba no constituye un centro primario de origen del cultivo del frijol. Existen sin embargo algunas circunstancias especiales en Cuba que podrían explicar estos niveles de diversidad, además del hecho de que las variedades locales provengan originalmente de ambos centros primarios de domesticación. Estas circunstancias están relacionadas principalmente con el hecho de que en Cuba los consumidores no son tan rigurosos en relación a la forma, tamaño y tonalidad de los frijoles, lo que permite a los agricultores cultivar materiales con una amplia diversidad de tamaños y tonalidades en los granos, sin que esto afecte la comercialización, a excepción de las variedades de granos que se consumen preferentemente de grano pequeño. Por otro lado, en su afán por probar nuevas variedades en sus fincas, algunos agricultores utilizan como semilla los granos de frijol que son entregados

AGRONOMÍA MESOAMERICANA 17(3): 369-382. 2006 
a los cubanos a través de la canasta básica de alimentos, que en muchas ocasiones son importados. De esta manera, se pueden haber introducido nuevos materiales provenientes de otros lugares del mundo (Chaveco $2004^{5}$ ). Por último, algunas de las de variedades locales manejadas actualmente en las comunidades rurales son en realidad variedades comerciales que fueron "acriolladas" con el tiempo por los agricultores y que provienen en muchos casos de programas de mejora de centros de investigación internacionales, que utilizan parentales provenientes de otros países.

Los métodos usados para determinar la diversidad en este trabajo fueron eficientes, lo que corrobora que los marcadores RAPD constituyen una herramienta útil en el estudio de la diversidad genética de frijol, con la ventaja adicional de que no está influenciada por el medio ambiente. El empleo de los marcadores morfo agronómicos sin embargo sigue siendo vital para el análisis de esta diversidad y los caracteres que la determinan, información que resulta crítica en los trabajos de mejoramiento y conservación de los recursos fitogenéticos y en particular del frijol común, así como en los estudios de impacto de procesos que influyen sobre la agrobiodiversidad en comunidades rurales y urbanas.

Los resultados de este trabajo mostraron que las variedades locales de frijol presentes en esta y otras comunidades rurales cubanas deben ser incluidas en los programas de mejoramiento genético participativo y convencional del cultivo. Su valor no sólo radica en la diversidad que presentan, de acuerdo a los resultados de este estudio, sino también en que han sido conservadas y seleccionadas durante años por los agricultores en sus fincas, por lo que pueden presentar características de interés para éstos y un buen nivel de adaptación a las condiciones edafoclimáricas y productivas de sus comunidades. Por lo anterior, éstas y otras variedades locales cubanas han sido incluidas en estrategias de conservación y diseminación de la diversidad genética de frijol, que comienzan con la colecta y estudio de la diversidad genética de estas variedades locales. Esto ha permitido que sean incluidas en las colecciones de germoplasma cuyo acceso es

5 CHAVECO, O. 2004. Feria de Diversidad de Frijol, 2004. Estación Territorial de Investigaciones Agropecuarias de Holguín. Cuba. Comunicación personal. facilitado a los agricultores por medio de metodologías como la selección participativa de variedades por agricultores en ferias de diversidad y experimentación in situ. Estas metodologías han facilitado la introducción, adopción, conservación in situ y diseminación de estas variedades, no solo en sus comunidades de origen, sino en otras, donde han sido seleccionadas por presentar buenos rendimientos, menos afectaciones a enfermedades y menor ciclo de cultivo (Miranda 2005), además de otras múltiples cualidades específicas de interés para los agricultores (Lamin 2005). Esto ha generado un proceso en el que la conservación, uso y diseminación de las estas variedades, se convierte en una fuente de bienestar económico para los agricultores y un modo eficiente de conservación in situ de variedades locales.

\section{LITERATURA CITADA}

ALMEKINDERS, C.; LOUWAARS, N. 1999. Farmers' seed production: New approaches and practices. London, Ed. Intermediate Technology Publications Ltd., 289 p.

ALZATE-MARIN, A. L.; COSTA, M. R.; SARTORATO, A.; DEL PELOSO, M. J:, BARROS, E. G.; ALVES, M. 2003. Genetic variability and pedigree analysis of brazilian common bean elite genotypes. Scientia Agricola 60: 283.290 .

BAI, Y.; MICHAELS, T.E.; PAULS, K.P. 1998. Determination of genetic relationships among Phaseolus vulgaris population in a conical cross from RAPD marker analysis. Mol. Breed. 4: 395-406.

BEEBE, S.; SKROCH P.W.; THOME J.; DUQUE M.C.; PEDRAZA, F.; NIENHUIS J. 2000. Structure of genetic diversity among common bean landraces of Middle American origin based on correspondence analysis of RAPD. Crop Sci. 40(1): 264-273.

BEEBE, S.E.; OCHOA, I.; SKROCH, P.W.; NIENHUIS, J.; TIVANG, J. 1995. Genetic diversity among common bean breeding lines developed for Central America. Crop Sci. 35 (4): 1178-1183.

CAIXETA, M.; ALVES. 2001. Caracterização da diversidade genética em feijão por meio de marcadores RAPD. Pesq. Agropec. Bras., Brasília, 36 (2):381-385. 
CASTIÑEIRAS, L.; ESQUIVEL, M.; LIOI, L.; HAMMER, K. 1991. Origin, diversity and utilization of the Cuban germoplasma of common bean (Phaseolus vulgaris L.). Euphytica 57: 1-8.

CASTIÑEIRAS, L.; PÉREZ NASSER, N.; PIÑERO, D. 1994. The origin of Phaseolus vulgaris L. in Cuba: phaseolin patterns and their relationship with morphoagronomical traits. Plant genetic resources Newsletter 99: 25-28.

CATTAN-TOUPANCE, I.; MICHALAKIS, Y.; NEEMA, C. 1998. Genetic structure of wild bean populations in their South.Andean center of origin. Theoretical and Applied Genetics. 96: 844-851.

DEFOER, T. 1998. Farmer Participation and Crop improvement. 1998. In: L. Bacci; F.N. Reyniers eds. The future of photoperiodical cereals for sustainable production in the semiarid tropics of Africa. Florence, Italy, 27-30 April. CIRAD, Montpellier, France. p.149-161.

DICE, L. R. 1945. Measures of the amount of ecologic association between species. Ecology 26: 297-302.

DUARTE, J. M.; DOS SANTOS, J. B.; MELO, L. C. 1999a. Comparison of similarity coefficients based on RAPD markers in the common bean. Genetics and Molecular Biology 22(3):427-432.

DUARTE, J. M.; DOS SANTOS, J. B.; MELO, L. C. 1999b. Genetic divergence among common bean cultivars from different races based on RAPD markers. Genetics and Molecular Biology 22 (3): 419-426.

DURÁN, L.A.; BLAIR, M.W.; GIRALDO Z., M.C.; MACCHIAVELLI, R.E.; PROPHÈTE, E.; NIN, J.C.; BEAVER, J.S. 2005. Morphological and molecular characterization of common bean landraces and cultivars from the Caribbean. Crop Science 45(4): 1320-1328.

EMYGDIO, B. M.; ANTUNES, I. F.; CHOER, E.; NEDEL, J. L. 2003. Eficiência de coeficinetes de similaridade em genotípos de feijão mediante marcadores RAPD. Pesq. Agropec. Bras., Brasília 38 (2): 243-250.

FE, C.; RÍOS, H.; ORTIZ, R.; MARTÍNEZ, M.; ACOSTA, R.; PONCE, M.; MIRANDA, S.; MORENO, I.; MARTÍN, L. 2003. Las ferias de agrobiodiversidad: Guía metodológica para su organización y desarrollo en Cuba. Cultivos Tropicales 24 (24): 95-106.

FRANCO, C.; CASSINI, S. T. A.; MONTRAZZI, F. C.; TSAI, S. M. 1998. RAPD analysis of common bean
(Phaseolus vulgaris L.) cultivars and evaluation of common bacterial blight (CBB) and wild fire (WF) resistance. Annual Report of Bean Improvement Cooperative 41:143-144.

GARCÍA, A.; MAÑALICH, I.; PICO, N.; QUIÑONES, N. 1997. La sustitución de importaciones de alimentos: una necesidad impostergable (primera parte), Investigación económica 3(1): 1-45.

GEPTS, P.; BLISS, F. A.1986. Phaseolin variability among wild and cultivated common beans (Phaseolus vulgaris L.) from Colombia. Economic Botany 40 (4):469-478.

GEPTS, P.; OSBORN, T. C.; RASCA, K.; BLISS, F. A. 1986. Phaseolin-protein variability in wild forms and landraces of common bean (Phaseolus vulgaris L.): evidence for multiple centers of domestication. Economic Botany40 ( 4):451-468.

HARDON, J. BOEF, W.F. 1993. Cultivating knowledge. Genetic Diversity, farmer experimentation and crop research. In: Hardon, J. eds. Linking farmers and breeders in local crop development. p. 64-72.

HERNÁNDEZ, A.; PÉREZ, J. M.; BOSCH, D.; RIVERO, L. 1999. Nueva edición de clasificación genética de los suelos de Cuba. Ed. AGRINFOR. Ciudad de la Habana, Cuba. 64 p.

KAISER, H. 1960. The application of electronic computers to factor analysis. Educational and Psychological Measurement 20:141-151.

LAMIN, N.G. 2005. Evaluación del impacto del fitomejoramiento participativo sobre los sistemas locales del frijol común (Phaseolus vulgaris L.) en La Palma, Pinar del Río, Cuba. UNAH, La Habana. 75 p.

LIN, C.S.; POUSHINKY, G.; JUI, P. 1983. Simulation study of three adjustment methods for the Modified Augmented Designand comparison with the Balanced Lattice Square Design. Journal of Agricultural Sciences 100: 527-534.

MARTI, B.; FERREIRA, I.; CHOER, E; NEDEL, J. M. 2003. Efiência de coeficientes de sinilaridade em genótipos de feijão mediante marcadores RAPD. Pesq. Agropec. Bras., Brasilia 28 (2): 243-250.

MÉTAILS, I.; AUBRY, C.; HAMON, B.; JALOUZOT, R.; PELTIER, D. 2000. Description and analysis of genetic diversity between commercial bean lines (Phaseolus vulgaris L.). Theoretical and Applied Genetics 101 (8): 1207-1214.

AGRONOMÍA MESOAMERICANA 17(3): 369-382. 2006 
MIRANDA, S.; SOLERI, D.; ACOSTA, R.; RIOS, H. 2003. Caracterización de los sistemas locales de frijol y maíz en La Palma, Pinar del Río. Cultivos Tropicales 24(4): 41-47.

MIRANDA, S. 2005. Efectividad de la selección participativa de variedades como una alternativa para el fortalecimiento de los sistemas locales de semillas de frijol común (Phaseolus vulgaris L.) en una comunidad rural cubana. Tesis MSc. Facultad de Biología, Universidad de la Habana. 76 p.

MUÑOZ, G.; GIRALDO, G.; DE SOTO, J.F. 1993. Descriptores varietales: Arroz, frijol, maíz, sorgo. CIAT. Cali, Colombia. 169 p.

NIENHUIS, J.; TIVANG, J.; SKROCH, P.W.; DOS SANTOS, J.B. 1995. Genetic relationships among cultivars and landraces of lima bean (Phaseolus lunatus L.) as measured by RAPD markers. J. Amer. Soc. Hortic. Sci. 120 (2): 300-306.

ORTIZ, R.; RÍOS, H.; PONCE, M.; VERDE, G.; ACOSTA, R.; MIRANDA, S.; MARTÍN, L.; MORENO, I.; MARTÍNEZ, M.; FE, C.; VARELA, M. 2003. Impactos de la experimentación campesina en cooperativas de producción agropecuaria de La Habana. Cultivos Tropicales 24 (4): 115-122.

RIOS, H.; WRIGHT, J. 2000. Primeros intentos para estimular los flujos de semillas en Cuba. LEISA 15 (3): 3738.

ROSAS, J. C. 1998. El cultivo del frijol común en América tropical. Zamorano Academic Press, Tegucigalpa, Honduras. 52 p.

SINGH, S. P.; NODARI, R.; GEPTS, P. 1991a. Genetic diversity in cultivated common bean: I. Alloenzymes. Crop Sci.31:19-23. Singh S. Broadening the genetic Base of Common Bean Cultivars: A review. Crop Sci. 31:1659-1675.

SINGH, S. P.; GUTIERREZ, J. A.; MOLINA, A.; URREA, C.; GEPS, P. 1991b. Genetic diversity in cultivated common bean: II. Marker based analysis of morphological and agronomic traits. Crop Sci. 31:23-29.
SINGH, S.P.; TERÁN, H.; MUÑOZ, C.G.; TAKEGAMI, J.C. 1999. Two cycles of recurrent selection for seed yield in common bean. Crop Sci. 39:391-397.

SINGH S. 2001. Broadening the genetic base of common bean cultivars: A review. Crop Sci. 41:1659-1675.

SKROCH, P.W.; NIENHUIS, J.; BEEBE, S.; TOHNE, J.; PEDRAZA, F. 1998. Comparison of mexican common bean (Phaseolus vulgaris L.) core and reserve germplasm collections. Crop Sci. 38 (2): 488-496.

TATINENI, V.; CANTRELL, R. G.; DAVIS, D.D. 1996. Genetic diversity in elite cotton germplasm determined by morphological characteristics and RAPDs. Crop Sci.36:186-192.

TOHME, J.; GONZÁLEZ, D. O.; BEEBE, S.; DUQUE, M. C. 1996. AFLP analysis of gene pools of a wild bean core collection. Crop Sci.36:1375-1384.

VASCONCELOS, M. J. V.; BARROS, E. G.; MOREIRA, M. A.; VIERA, C. 1996. Genetic diversity of the common bean Phaseolus vulgaris. L. determined by DNA-based molecular markers. Brazilian Journal of Genetics, Ribeirão Preto. 19:447-451.

VERA, C. M.; PAREDES, M. C.; BECERRA, V. V. 1999. Estudio comparativo de diversidad morfológica, isoenzimática y RAPDs dentro y entre clases comerciales de fréjol chileno (Phaseolus vulgaris L.). Agricultura Técnica 59 (4): 247-259.

VOYSEST, O.; DESSERT, M. 1991. Bean cultivars: Classes and commercial seed types. In: Van Schoonhoven, A.; Voysest, O. eds. Common beans: research for crop improvement. CIAT, Cali, Colombia, 119 p.

VOYSEST, O. 2000. Mejoramiento genético del fríjol (Phaseolus vulgaris L.). Legado de variedades de América Latina 1930-1999. CIAT, Cali, Colombia. 195 p.

WILLIAMS, J. G. K.; KUBELIK, A. R.; LIVAK, K. J.; RAFALSKI, J. A.; TIGEY, S. V. 1990. DNA polymorphisms amplified by arbitrary primers are useful as genetic markers. Nucleic Acids Research, Oxford, UK 18: 6531-6335. 